\title{
Movement Differential Equation of Seed Roller which Has Been Installed Stake Accelerator on the Roll Box of Gin Machine
}

\author{
Sarimsakov Akramjon, Muradov Rustam, Umarov Akmal, Kurbanov Dilmurat \\ Namangan Institute of Engineering and Technology, Namangan, Uzbekistan \\ Email: s.akram_82@mail.ru,rustam.m@list.ru, akmal.umarov@mail.ru
}

How to cite this paper: Akramjon, S., Rustam, M., Akmal, U. and Dilmurat, K. (2018) Movement Differential Equation of Seed Roller which Has Been Installed Stake Accelerator on the Roll Box of Gin Machine. Engineering, 10, 521-529.

https://doi.org/10.4236/eng.2018.108038

Received: July 1, 2018

Accepted: August 12, 2018

Published: August 15, 2018

Copyright $\odot 2018$ by authors and Scientific Research Publishing Inc. This work is licensed under the Creative Commons Attribution International License (CC BY 4.0). http://creativecommons.org/licenses/by/4.0/

\begin{abstract}
In the article stake accelerator has proposed on the side of the roll box in order to increase the productivity of the gin machine. The effect to the raw material of the proposed stakes was studied. Movement differential equation of the seed roller was made up and necessary graphics were taken based on laws.
\end{abstract}

\section{Keywords}

The Cotton, Gin, Seed, Fiber, Saw, Gridiron, Roll Box, Seed Roller, Speed, Quality, Efficiency, Productivity, Equation, Pressure, Density, Strength

\section{Introduction}

The production of cotton products and the cotton industry occupies an important place in the economy of Uzbekistan, as a result of which a number of decrees and higher-level decisions on the cardinal transformation of this sphere of the economy have been adopted lately [1] [2], and the output of cotton for the last 5 years has been declining its consumption within the country is gradually increasing [3]. The country is striving to rebuild its economy with the production of deep processing of cotton, bringing raw cotton to finished products. Therefore, scientific research aimed at improving the quantitative and qualitative indicators of cotton products for the country is of great importance.

The formation of a roller of the cotton and its rotation in the gin chamber depends on a number of factors in the process of extracting cotton fiber from cotton seed. Some of the main factors are the density and fibrousness of the seed roller, the moisture content of the seeds, and others. In addition, it must be taken into account of the friction create which roll box made up with its walls under 
the pressure of seed roller. These factors have an impact on the productivity of gin machine and the fiber quality.

\section{Defects of Gin Machine}

It has proven that the increase of the productivity of gin machine is accompanied by an increase in the density of the seed roller [4]. However, with the increase in the density of the limits of the increase in productivity, and productivity begins to decline. It is the force of friction in the lateral direction of raw materials related to the decrease in the speed of rotation of the torus density $550 \div$ $600 \mathrm{~kg} / \mathrm{m}^{3}$, stopping of the process has completely proved [5].

\section{New Proposed of Gin Machine}

For the loosing of above omission, 30 sawing gin machine has been prepared by the researchers of Namangan Institute of Engineering and Technology because of learning by experimental way of the cycling the configuration which installed on the side of roll box of gin machine to the efficiency of the speed of seed roller. Experiments were held at the research laboratory of the department of "Technology of the primary process of natural fibers".

It has determined that there is not a great difference between them when compared the rotation of the speed of seed roller which formed in the roll box of 30 sawing and 130 sawing gins. As well as, when 30 sawing and 130 sawing gins work, there is same productivity of gin which is through to the one saw. That's why experience was held on the 30 sawing gin machine [6] (Figure 1).

Gin 30 saw the experimental device designed to hold the camera as follows. Preparing for the experience of 30 cotton gin devices placed in a hopper 1 . Bunker 1 and 2 support roller drum 3 is transferred to the stake, stake drum 3 cotton recreated in hit a 4-clock clean the gutter working camera out of 5, 6. In the working camera, cotton exclusive 10 teeth using chaining raw material protector. Serrated trapped between the fibers 9 gridirons, cotton trim fit between gridirons coming down with the weight of the seeds are. Exclusive brush fibers are trapped teeth 13 using a drum. In the device $3 \mathrm{~kW}$ engine has installed for working the brush drum 13. $5.5 \mathrm{~kW}$ engine has installed for working the brush drum 10. It is consisted of the roller 15 and engine 17 which mounted to the side of the camera, as well as working stake device [7].

Foreign workers into the camera installed on the side of the accelerators and a range of 400 to 200 on the basis of research of the republic $\mathrm{r} / \mathrm{min}$. The working speed of the camera is set to the side of the acceleration and the length of the stakes different. In addition, taking into account the relative position of stakes saw their length of experience of training are different in length [8]. Working to turn the unit on the side of the camera was adjusted to $0.75 \mathrm{~kW}$ motor.

Movement of workers using a camera placed behind the roller. Accelerators installed on the side of the roll box and the raw materials into the roller tachometer.

The length of the stakes on the side of the gin roll box is set to the length of 


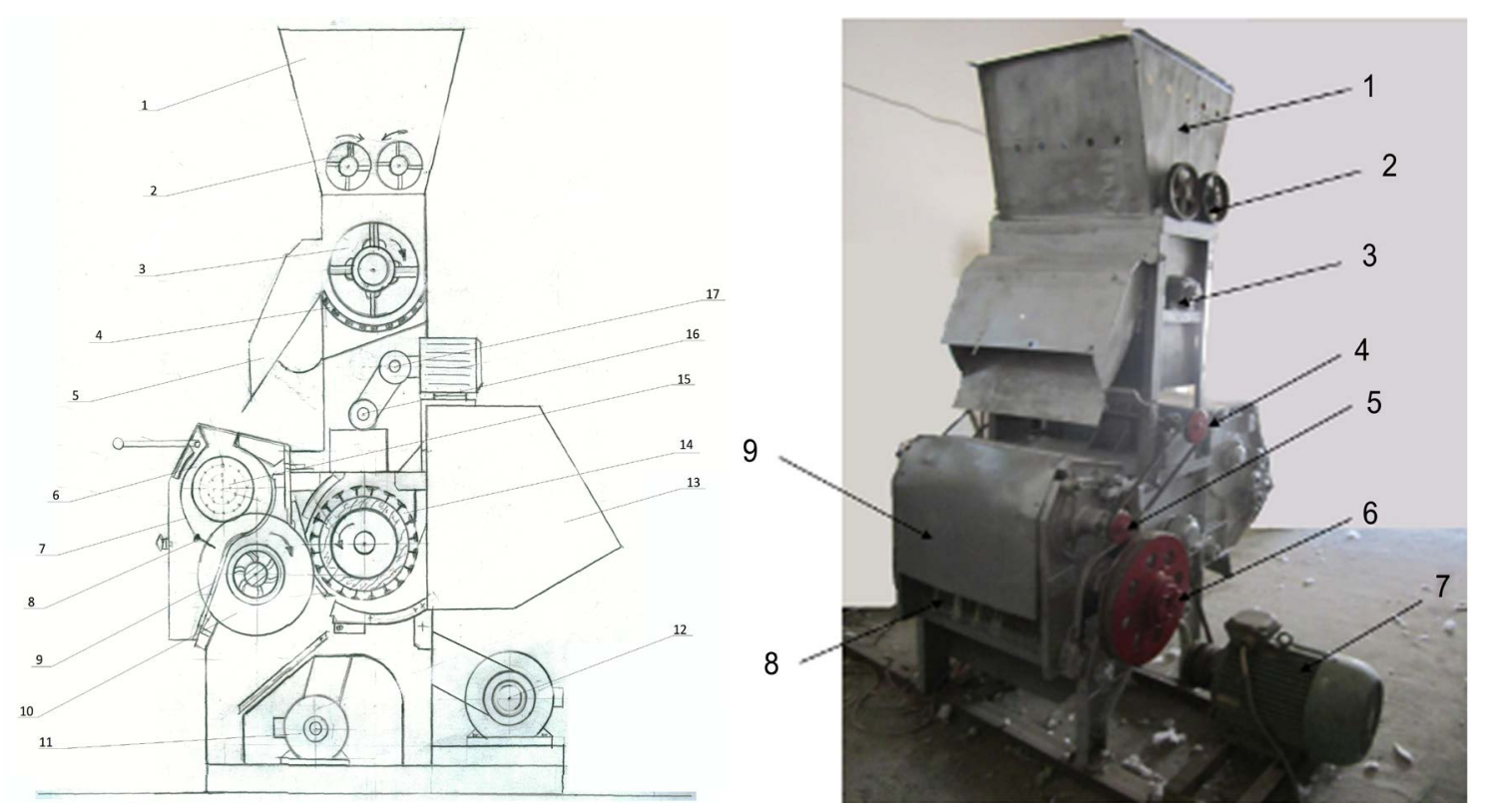

Figure 1. Scheme and appearance of the gin machine construction which can held 30 sawing experiment. 1-hopper, 2-support rollers, 3-stake drum, 4-mesh surface, 5-tray, 6-roll box, 7-apron, 8-seeds, 9-gridirons, 10-blade cylinder, 11-engines (into the brush drum), 12 engine (into the sawing a drum), 13-fiber assembly of the camera, 14-the brush drum, 15-the device mounted to the side of the working camera, 16-cycling roller of the device which mounted to the side of the working camera, 17 -engine ( $0.75 \mathrm{~kW}$ working to transform the unit is set to the side of the camera).

the stakes h1-10 $\mathrm{mm} \mathrm{h} 2-15 \mathrm{~mm}$.

Figure 2 is a diagram and a general view of the proposed sticks to the sidewall of the gin roll box.

Experiments demon side of the device installed stakes long prepared 1-variant did not have a good effect. A long time worked stakes cotton rope to stakes cases. As a result, the 1 st version wasn't made experiments.

Gin was fitted to the side of the roll box short stakes set out a detailed study concluded that the results of the experiments. China is set to the side of the roll box of raw stake significant costs of the motor shaft [9].

\section{The Theoretical Research of the Efficiency to the Seed Roller of the Stake Impact which Installed in the Gin Roll Box}

Gin unit installed in the roll box judge roller theoretical study of the impact of raw materials.

Gin cameras set up in the roll box, the judge accelerator seed roller differential theoretical equation [10].

Figure 3 shows the forces of action of the proposed stick accelerators on the rotation of seed roller.

1) Some of the seed roller rotation as a continuous single-sex environment.

2) Working on either side of the camera, the motion judge cyclotron seed roller more quickly and they were together. 


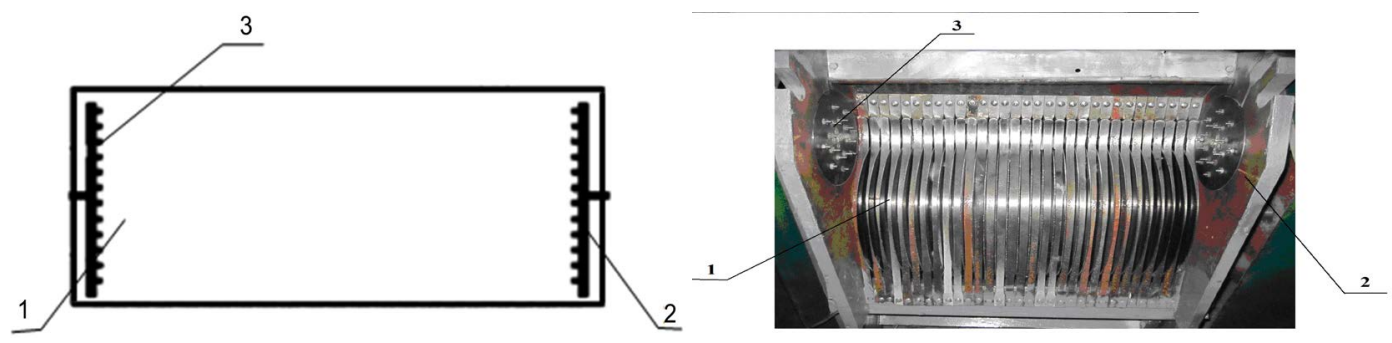

Figure 2. Scheme and appearance of the stakes installed on the side of the gin roll box (Patent FAP 00990). 1-roll box, 2-on the side of the roll box, 3-stakes.

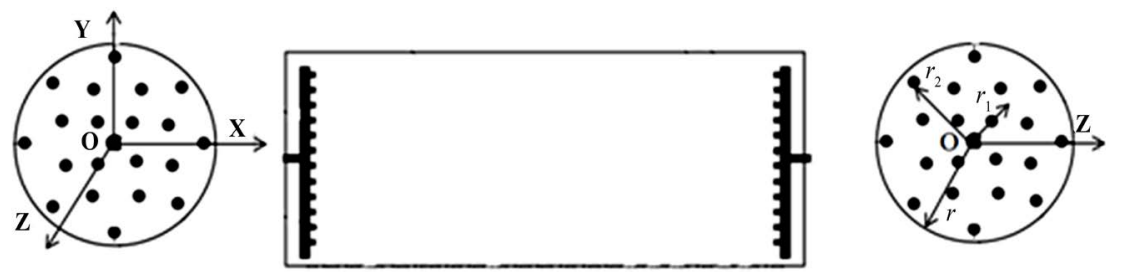

Figure 3. Mathematical model of the movement of seed roller, we accept the following terms and conditions.

3) The judge accelerator, along the circle radius $r_{1}$, seed roller outer radius $r_{2}, r$ seed roller voluntary-sectional radius of the circumference.

4) The judge acceleration of raw material along the axis $\mathrm{OZ}$ of the shaft impact workers decreases towards the center of the camera.

5) Depending on the movement of seed roller fixed.

Mathematical model of the motion of seed roller has the following steps:

Seed roller motion differential equations Nave-Stoke equations we make cylindrical coordinates (Figure 4).

According to the scheme, preset in Figure 4, we compose the Euler equations, which have the form:

$$
\begin{aligned}
& \rho\left(\frac{\partial V_{z}}{\partial t^{2}}+V_{r} \frac{\partial V_{r}}{\partial r}+\frac{V_{\theta}}{r} \cdot \frac{\partial V_{r}}{\partial \theta}-\frac{V_{\theta}^{2}}{r}+V_{z} \frac{\partial V_{z}}{\partial Z}\right) \\
& =\frac{\partial V_{z}}{\partial r}+\mu\left\{\frac{\partial}{\partial r}\left[\frac{1}{2} \cdot \frac{\partial}{\partial r}\left(r \cdot V_{r}\right)+\frac{1}{r^{2}} \cdot \frac{\partial^{2} V_{r}}{\partial \theta^{2}}-\frac{2}{r^{2}} \cdot \frac{\partial^{2} V_{\theta}}{\partial r}+\frac{\partial^{2} V_{r}}{\partial Z^{2}}\right]\right\} ; \\
& \rho\left(\frac{\partial V_{z}}{\partial t}+V_{r} \frac{\partial V_{r}}{\partial r}+\frac{V_{\theta}}{r} \cdot \frac{\partial V_{r}}{\partial \theta}-\frac{V_{\theta}^{2}}{r}+V_{z} \frac{\partial V_{z}}{\partial Z}\right) \\
& =\frac{\partial P}{\partial r}+\mu\left\{\frac{\partial}{\partial r}\left[\frac{1}{2} \cdot \frac{\partial}{\partial r}\left(r \cdot V_{r}\right)+\frac{1}{r^{2}} \cdot \frac{\partial^{2} V_{r}}{\partial \theta^{2}}-\frac{2}{r^{2}} \cdot \frac{\partial V_{\theta}}{\partial r}+\frac{\partial^{2} V_{r}}{\partial Z^{2}}\right]\right\} ; \\
& \rho\left(\frac{\partial V^{2}}{\partial Z}+V_{z} \frac{\partial V_{2}}{\partial \theta}+V_{z} \frac{\partial V_{Z}}{\partial Z}\right) \\
& =-\frac{\partial P}{\partial Z}+\mu\left\{\frac{1}{r} \cdot \frac{\partial}{\partial r}\left(Z \cdot \frac{\partial V_{Z}}{\partial r}+\frac{1}{r^{2}} \cdot \frac{\partial^{2} V_{2}}{\partial \theta^{2}}+\frac{\partial^{2} V_{2}}{\partial Z^{2}}\right)\right\}
\end{aligned}
$$

Seed roller choice for the environment is considered as connectivity equation is written as follows: 


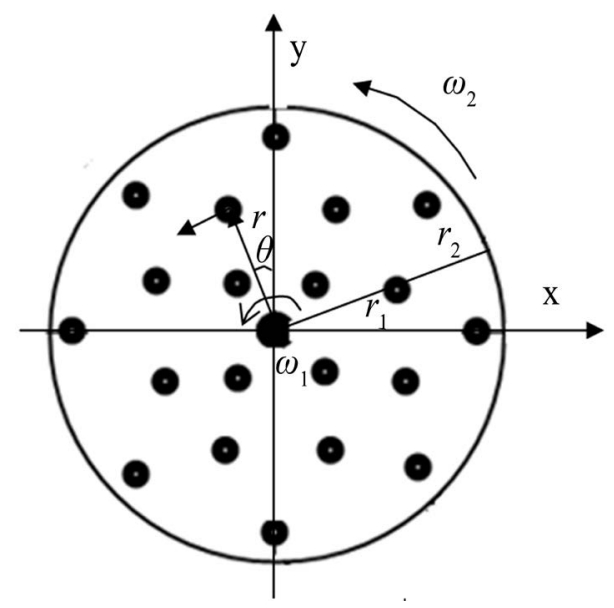

Figure 4. Convert movement scheme of seed roller.

$$
\frac{1}{r} \cdot \frac{\partial}{\partial r}\left(r \cdot V_{r}\right)+\frac{1}{r} \cdot \frac{\partial V_{\theta}}{\partial \theta}+\frac{\partial V_{z}}{\partial Z}=0
$$

Seed roller velocity components $V R=0 ; V Z=0$, again do not know what direction the pressure forces attention $P=P(r)$.

Connectivity equation as follows:

$$
\frac{1}{r} \cdot \frac{V_{\theta}}{\partial \theta}=0
$$

Nave Sto'ks equations are written as follows:

$$
\begin{gathered}
-\rho \frac{V_{\theta}^{r}}{r}=\frac{\partial P}{\partial r}+\mu\left\{+\frac{\partial}{\partial r}\left(\frac{Z}{r^{2}} \cdot \frac{\partial V_{\theta}}{\partial r}\right)\right\} ; \\
0=\frac{1}{2} \frac{\partial P}{\partial \theta} \cdot \frac{\mu}{\rho}\left\{\frac{\partial}{\partial r}\left(\frac{1}{r} \frac{\partial}{\partial r}\left[r \cdot V_{\theta}\right]\right)+\frac{\partial^{2} V_{\theta}}{\partial Z^{2}} 5\right\}
\end{gathered}
$$

(5) - we can write the following:

$$
\frac{\partial^{2} V_{\theta}}{\partial r^{2}}+\frac{\partial V_{\theta}}{\partial r}-\frac{V_{\theta}}{r^{2}}=0
$$

(6) - for the typical equation-Eyler, seek private solutions;

$$
\begin{gathered}
V_{\theta}=r^{K} \\
(7) \Rightarrow(6) ; \quad K(K-1)+K-1=0 \Rightarrow \begin{array}{c}
K_{1}=-1 \\
K_{2}=1
\end{array}
\end{gathered}
$$

Root: $V_{\theta 1}=r ; V_{\theta 2}=\frac{1}{r}$;

General solution: $V_{\theta}=A \cdot r+\frac{B}{r}$

A, B-unknown constants of the following boundary conditions:

$$
\begin{gathered}
r=r_{1} \text { да } V_{\theta}\left(r_{1}\right)=\omega_{1} \cdot r_{1} \cdot e^{-a z} \\
r=r_{2} \partial a V_{\theta}\left(r_{2}\right)=\omega_{2} \cdot r_{2}, \theta \leq Z \leq \frac{L}{2} ;
\end{gathered}
$$




$$
r=r_{2} \text { да } V_{\theta}\left(r_{2}\right)=\omega_{2} \cdot r_{2}, \theta \leq Z \leq \frac{L}{2} ;
$$

Generally solution:

$$
V_{0}=\frac{\omega_{2} r_{2}^{2}-\omega_{1} r_{1}^{2} e^{-\alpha z}}{r_{2}^{2}-r_{1}^{2}} \cdot r+\frac{\left(r_{1} r\right)_{2}^{2}\left(\omega_{2}-\omega_{1} \cdot e^{-\alpha z}\right)}{\left(r_{1}^{2}-r_{2}^{2}\right) r}
$$

where: $V_{0}$-grade material layer-raw material exchange rate $(\mathrm{m} / \mathrm{s}) ; r$-the radius of the velocity of the investigated layer; $r_{1}$-the radius of the circumference of the stake acceleration; $r_{2}$-the radius of the raw-material's roller; $\omega_{1}$-the rate of acceleration rotational angle of the stake; $\omega_{2}$-seed roller Garden speed of the angle of rotation; $z$ - gin roll box on the left edge of the reading range.

$$
0 \leq \mathrm{Z} \leq \frac{L}{2}
$$

(9) by using the formula $v_{1}=\omega_{1} \mathrm{r}_{1} e^{--} \alpha \quad \mathrm{Z}$ and $v 2=\omega 2 \mathrm{r} 2-$, and raw materials roller voluntary $r$-radius allows you to determine the speed of a layer.

The equation of the strength of the pressure on seed roll

1) Normal pressure

$r$-radius optional layer of seed roller in the normal pressure (4) - to determine the equation:

$$
\begin{gathered}
\frac{\partial P}{\partial r}=\mu \frac{\partial}{\partial r}\left(\frac{2}{r^{2}} \frac{\partial V_{0}}{\partial r}\right)-\rho \frac{V_{\theta}^{2}}{r} \\
\frac{\partial P}{\partial r}=\mu \frac{\partial}{\partial r}\left(\frac{2}{r^{2}} \cdot \frac{2 B}{r^{3}}\right)-\rho \frac{\left(A \cdot r+\frac{B}{r}\right)^{2}}{r}
\end{gathered}
$$

or

$$
\begin{aligned}
P= & P_{0}-\frac{4 \mu \cdot B}{r_{1}^{5}}+\rho\left[\frac{A r_{1}^{2}}{2}+2 A B \ln r_{1}-\frac{B^{2}}{2 r_{1}^{2}}\right] \\
& +\frac{4 \mu B}{r^{5}}-\rho\left(\frac{A^{2} r^{2}}{2}+2 A B \ln 2-\frac{B^{2}}{2 r^{2}}\right)
\end{aligned}
$$

Also: Thus, the seed roller voluntary-aquifer pressure: it will be possible to determine the expression.

$\rho$-seed roller density $\left(\mathrm{kg} / \mathrm{m}^{3}\right) ; \mu$-seed dynamic viscosity coefficient.

2) To determine the strength of the pressure. The strength of the pressure on seed roller an effort to make sure the motion of the common voltage is defined by the equation:

$$
P_{r \theta}=\mu\left(\frac{1}{r} \frac{\partial V_{\theta}}{\partial_{\theta}}+\frac{\partial V_{\theta}}{\partial r}-\frac{V_{\theta}}{r}\right)
$$

Here $\frac{\partial V_{\theta}}{\partial_{\theta}}=0$

$$
P_{r \theta}=\mu\left(\frac{\partial V_{\theta}}{\partial r}-\frac{V_{\theta}}{r}\right)
$$


$\frac{\partial V_{\theta}}{\partial r}$ is determined by taking into account meddles by pressing (9)

$$
P_{r \theta}=-\frac{2 \mu B}{r^{2}}
$$

By using (14) the seed roller willing to consider it tries layer voltage.

\section{Results}

The solution of the equations is made on a computer with the Mapple 2015 program shown in Figures 5-7, which show the changes in the process parameters when the initial parameters are changed.

Figure 5 shows the dependence of the cross-sectional coefficient of the seed roller, the cutting radius, the left edge of the gin wall is made rotary, where $1, \mathrm{z}=$ $0 ; 2-\mathrm{z}=0.1 ; 3-\mathrm{z}=0.2 ; 4-\mathrm{z}=0.4 ; 5-\mathrm{z}=0.5 ; 6-\mathrm{z}=0,5 \mathrm{~m}$-length of the bells mounted on the rotating wall. Figures 6 and 7 show the dependence of the lateral pressure and the normal seed pressure on the surface of the rotating wall when the wall radius varies with the length of the bell $1, \mathrm{z}=0 ; 2-\mathrm{z}=0.1 ; 3-\mathrm{z}=0.2 ; 4-\mathrm{z}$ $=0.4 ; 5-\mathrm{z}=0.5 ; 6-\mathrm{z}=0.5 \mathrm{~m}$.

\section{Conclusions}

Raising roller voluntary tried-layer speed demon $\mathrm{Z}$-axis left counts $=0 ; 0.1 ; 0.2$; 0.3; $0.4 ; 0.5 \mathrm{~m}$ cross section in Figure 5, the change in principle. Graphic shows roller axis at high speed toward the edge of the cut showing the increase in raw material toward the center roller rims. Raw materials roller $\mathrm{V}$ gear cutting, equipment and raw materials roller flow rate of $2-25 \mathrm{~m} / \mathrm{s} \mathrm{setting} \mathrm{accept.}$

These values decrease in raw materials towards the center roller practical experience.

Rotation axis cuts, raw materials roller rimmed gin saws cut surface wind speed $\mathrm{v}=2.5 \mathrm{~m} / \mathrm{s}$ found, the demons and the efficiency of the process are the same application. Figure 6 and Figure 7, the raw materials roller normal pressure in an effort to make sure that the forces of change in principle.

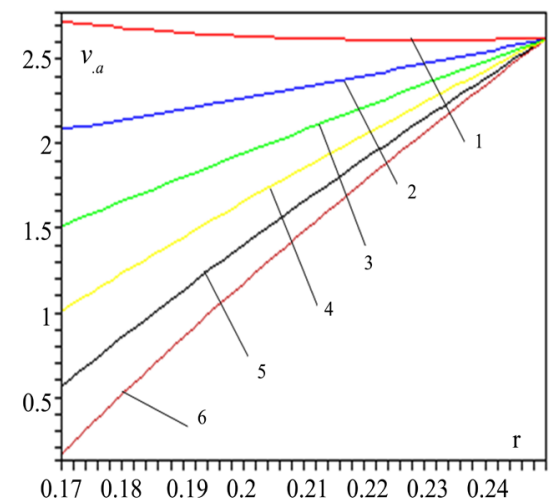

Figure 5. Seed roller exchange rate transverse, cutting radius, the demon left edge of the roll box $1, \mathrm{z}=0 ; 2-\mathrm{z}=0.1 ; 3-\mathrm{z}=0.2 ; 4-\mathrm{z}=0.4 ; 5-\mathrm{z}=0.5 ; 6-\mathrm{z}=0.5 \mathrm{~m}$ accounting change principle. 


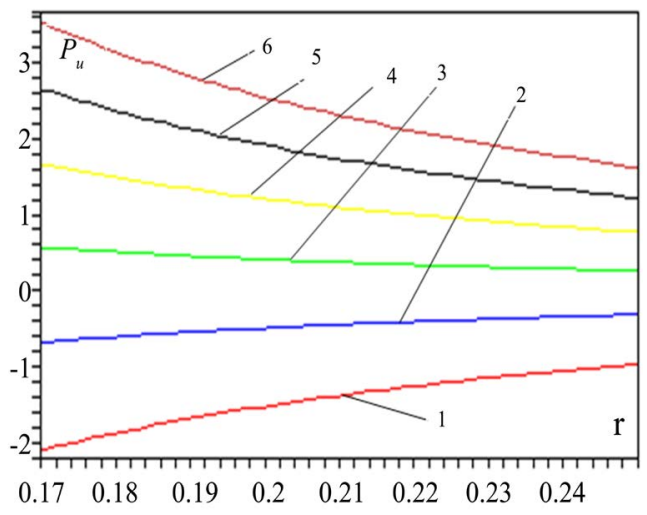

Figure 6. Seed roller an effort to make sure that the power of the printing direction, the devil left edge of the roll box $1, z=0 ; 2-z=0.1 ; 3-z=0.2 ; 4-z=0.4 ; 5-z=0.5 ; 6-z=0.5 \mathrm{~m}$ distance, transverse change depending on the radius of cutting principle.

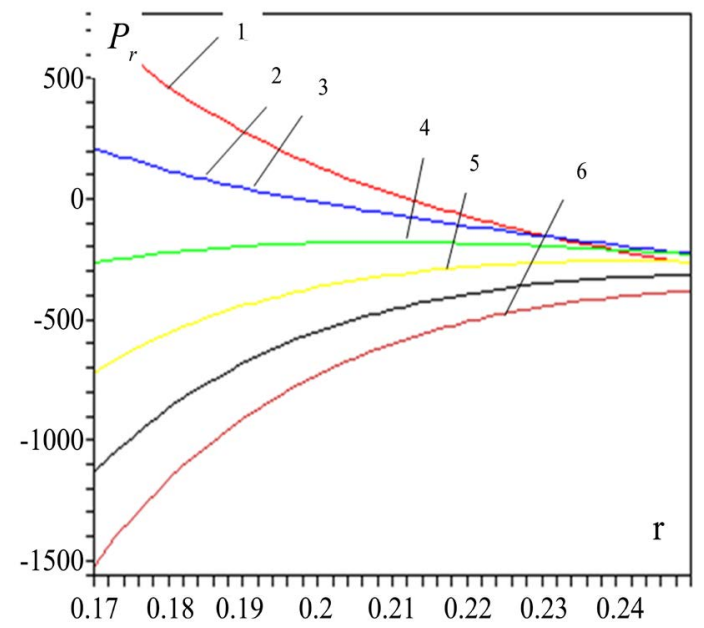

Figure 7. Seed roller sure that the power of a normal pressure, the demon left edge of the roll box $1, \mathrm{z}=0 ; 2-\mathrm{z}=0.1 ; 3-\mathrm{z}=0.2 ; 4-\mathrm{z}=0.4 ; 5-\mathrm{z}=0.5 ; 6-\mathrm{z}=0.5 \mathrm{~m}$ from transverse cutting radius variation principle.

According to Figure 6 again the power of the printing direction of raw materials roller toward the center of the transverse cross section of the flange discount would decrease between the center and the edge of the axis of rotation can be observed. In addition to raw materials roller cycle through the device, the pulse voltage is changing the entire length of the axis of rotation, which varies around $2 \div 3 \mathrm{~N}$.

These conditions are normal pressure were observed. Raw materials torus-rimmed pressure stabilized situation later. However, the raw materials would make sure the power of the torus central part of the changing pressure. This pressure towards the edge of the top of the central part of the roller-axis to point out the positive and negative signals' positive change, she said.

The raw material for the future by changing the speed of rotation of the device is learned through experience to become roller impact. In addition, drove into the unit stake productivity, raw materials and roller seeds are considered to have 
a working time of impact.

\section{Conflicts of Interest}

The authors declare no conflicts of interest regarding the publication of this paper.

\section{References}

[1] Prezident.uz (2017) About Measures on Cardinal Perfection of a Control System of a Cotton Industry. Decree of the President of the Republic of Uzbekistan of 28 November 2017 No. PP-3408. Press Service of the President of the Republic of Uzbekistan. Prezident.uz, Tashkent.

[2] Prezident.uz (2017) On Measures for the Accelerated Development of the Textile and Apparel-Knitting Industry. Decree of the President of the Republic of Uzbekistan of December 14, 2017 No. UP-5285. Press Service of the President of the Republic of Uzbekistan. Prezident.uz, Tashkent.

[3] Korabelnikov, A., Rudovsky, P., Sarimsakov, O. and Gaibnazarov. E. (2018) Dynamics of the Movement of Weed Particles in the Pulp During its Purification in Order to Establish the Rational Parameters of the Process. Materials of the International Scientific Conference. NamIIT, Namangan, 125.

[4] Burnashev, R.Z., Muradov, R. and Sarimsakov, O. (2001) Dynamic Task of Interaction of Raw Cotton with Working Bodies of Processing Machines. Journal of Problems of Mechanic, No. 3-4, 55.

[5] Abbazov, I., Sarimsakov, O., Khodjiev, M. and Mardonov. B. (2018) Effective Cleaning of Cotton Waste Produced at Cotton Cleaning Factories. American Journal ASCIT Communications, 5, 22-28.

[6] Sarimsakov, A.U., et al. (2015) Roll Box of Saw Gin Stand. Patent of the Republic of Uzbekistan No. FAP 00990.

[7] Sarimsakov, A. (2014) Modeling the Process of Interaction of a Moving Mass of Raw Cotton with a Rotating Saw Cylinder. Journal of "Problems of Mechanics", No. 2, 122-125.

[8] Sarimsakov, A., Karimov, A. and Mardonov, B. (2015) Ginning as an Aspect of the Technological Process. Academy of Natural Sciences, Moscow, 948-951.

[9] Karimov, A.I., Azizov, Sh. and Ismanov, M. (2014) Mathematical Modeling of the Technological Processes Original Processing of Cotton. International Journal of Innovation and Applied Studies, 6, 28-39. http://www.ijias.issr-journals.org/

[10] Sarimsakov, A., Karimov, A. and Mardanov, B. (2015) Contact Objectives of the Process of Interaction of Moving Cases of Cotton-Raw Material, with Rotating Saw Cylinder" Problems of Import Substitution. Collection of Materials of the International Scientific and Practical Conference, Ekaterinburg, 26-27 February 2015. 